\title{
Idiosyncratic nutrient requirements of cats appear to be diet-induced evolutionary adaptations*
}

\author{
James G. Morris \\ Department of Molecular Biosciences, School of Veterinary Medicine, University of \\ California, Davis, CA 95616, USA
}

Cats have obligatory requirements for dietary nutrients that are not essential for other mammals. The present review relates these idiosyncratic nutritional requirements to activities of enzymes involved in the metabolic pathways of these nutrients. The high protein requirement of cats is a consequence of the lack of regulation of the aminotransferases of dispensable $\mathrm{N}$ metabolism and of the urea cycle enzymes. The dietary requirements for taurine and arginine are consequences of low activities of two enzymes in the pathways of synthesis that have a negative multiplicative effect on the rate of synthesis. Cats have obligatory dietary requirements for vitamin D and niacin which are the result of high activities of enzymes that catabolise precursors of these vitamins to other compounds. The dietary requirement for pre-formed vitamin A appears to result from deletion of enzymes required for cleavage and oxidation of carotenoids. The $n-3$ polyunsaturated fatty acids (PUFA) requirements have not been defined but low activities of desaturase enzymes indicate that cats may have a dietary need for pre-formed PUFA in addition to those needed by other animals to maintain normal plasma concentrations. The nutrient requirements of domestic cats support the thesis that their idiosyncratic requirements arose from evolutionary pressures arising from a rigorous diet of animal tissue. These pressures may have favoured energy conservation through deletion of redundant enzymes and modification of enzyme activities to result in metabolites more suited to the cat's metabolism. However, this retrospective viewpoint allows only recognition of association rather than cause and effect.

\section{Nutrient requirements: Protein metabolism: Enzyme adaptation: Cats}

\footnotetext{
*A preliminary presentation of some of the material in the present review was made as Morris (2001).

Abbreviations: EUN, endogenous urinary N; MYBP, million years before the present; P-5-C, pyrroline5-carboxylate; RE, retinol equivalents.

Corresponding author: Dr James G. Morris, fax +1 530752 4698, email jgmorris@ucdavis.edu
} 


\section{Introduction}

Modern molecular techniques (for example, Johnson \& O’Brien, 1997; Murphy et al. 2000) have provided new insights into the evolution of cats and have supplemented concepts built upon fossil records. Animals with feline traits appeared about 30 million years before the present (MYBP), but ancestors of modern cats were not evident until the mid-Miocene period (15-20 MYBP). Dental and other characteristics suggest that these animals became true carnivores in a nutritional context at least 15 MYBP. DNA studies of the thirty-seven extant species of modern cats indicate that they evolved from approximately eight phylogenetic lineages within the past 10 to 15 MYBP (Johnson \& O’Brien, 1997; Pecon Slattery \& O’Brien, 1998). Within these lineages or species clades, speciation is comparatively recent as most fossil records of extant cats are less than 2 MYBP. The oldest fossil records are only 3-5 MYBP and some first appear as recently as $<100000$ years ago.

Domestic cats evolved within the past 4000 years from the African wild cat Felis sylvestris libyca (O'Brien \& Yuhki, 1999). Comparative genomics using cat-human radiation hybrid mapping have shown that the domestic cat genome organisation is remarkably conserved compared with the human genome (Murphy et al. 2000). Of all non-primate species examined, cats display the fewest number of chromosomal changes relative to man (O'Brien et al. 1999).

Domestic cats (Felis catus) are the only members of the family Felidae whose nutrition has been studied in any detail. The limited information available supports the view that other felids have similar nutritional requirements as those of domestic cats. It has generally been assumed that animals whose diet contains a wide range of foods are better adapted to changing environments than those that rely on a single or limited range of foods. Many highly successful mammals, such as rodents, are omnivorous in their dietary habits and adapt to varying diets and protein levels by modulating their metabolism. What is the basis for the success of true carnivores that are extreme specialists and have survived and evolved using a single type of food? A simple answer could be that animal tissue provides complete nutrition, and that restricted food availability is a trade-off for the high nutritive value of the food. Animals that eat other animals are not faced with deficiencies of essential nutrients, provided there is an abundance of prey. However, a diet of only animal tissue does not provide the balance of nutrients demanded by the body cells. If strict carnivores evolved adaptive metabolic pathways to handle this imbalance of nutrients, then these adaptations were a possible key to the success of carnivores.

\section{High protein requirement and amino acid metabolism}

Animal tissue, unlike food from plants, is low in carbohydrates and contains an excess of protein relative to the energy content. When the crude protein $(\mathrm{N} \times 6 \cdot 25)$ requirements of growing kittens are compared with other species, kittens require about 1.5 times the protein in the diet needed by chicks or pigs and these latter species deposit a higher proportion of the food $\mathrm{N}$ in tissue than kittens. However, a comparison of the protein requirements for adult maintenance is about 2 to 3 times higher in cats than in adult non-carnivores. This high protein requirement could be due to either (i) a higher than normal requirement for one or more of the essential amino acids, or (ii) a higher than normal requirement for $\mathrm{N}$. The essential amino acid requirements of kittens for growth have been measured and found (with one exception) to be quantitatively similar to those of other growing mammals (Rogers \& Morris, 1979). As a high requirement for an amino acid(s) does not account for the high protein requirement of cats, we are left with the second alternative, that cats require a high-protein diet because they have a high requirement for $\mathrm{N}$. 
Most omnivorous animals such as rats (Harper, 1965; Kaplan \& Pitot, 1970), pigs (Baker \& Speer, 1983), man (Krebs, 1972), chickens (Chandra et al. 1984), quail (Featherston \& Freedland, 1973), cockatiels (Koutsos et al. 2001) and the carnivorous fish that changes into a herbivorous fish (Mugil capito; Alexis \& Papaparaskeva-Papoutsoglou, 1986) when given diets low in protein, conserve amino acids by reducing the activities of the enzymes involved in the first step of amino acid catabolism. However, when cats were given high $(700 \mathrm{~g} / \mathrm{kg}$ ) and low $(170 \mathrm{~g} / \mathrm{kg})$ crude protein diets, there was little adaptation in the activities of the aminotransferases of general N metabolism to dietary protein (Rogers et al. 1977). This lack of enzymic adaptation in cats was similar to that reported in other carnivorous species such as trout (Cowey et al. 1981), alligators (Coulson \& Hernandez, 1983), vultures (Migliorini et al. 1973), and barn owls (Myers \& Klasing, 1999).

In addition, when omnivorous and herbivorous animals are given diets of varying protein contents the activities of the urea cycle enzymes are positively correlated with the level of protein in the diet of rats (Schimke, 1962, 1963; Freedland, 1964; Das \& Waterlow, 1974), children (Stephen \& Waterlow, 1968), pigs (Rosebrough et al. 1983; Edmonds \& Baker, 1987; Chen et al. 1999) and sheep (Payne \& Morris, 1969; Payne \& Laws, 1976, 1978). The increased activity facilitates disposal of the higher $\mathrm{N}$ loads from high-protein diets through the synthesis of urea from ammonia. A reduction of activity when a low-protein diet is consumed facilitates the conservation and re-utilisation of $\mathrm{N}$ for the synthesis of dispensable amino acids. For cats given a low-protein diet there was no reduction in the activity of the urea cycle enzymes (Rogers $e t$ al. 1977). Ammonia resulting from the deamination of amino acids by cats is continually diverted to urea and lost from the body pool, rather than contributing $\mathrm{N}$ for the synthesis of dispensable amino acids. The high protein requirement of cats is for dispensable N. The enzymes involved in the first irreversible step of the degradation of the essential amino acids are controlled; otherwise, cats would have a high requirement for essential amino acids as well as for N (Rogers \& Morris, 1980). A benefit to cats (and other true carnivores) arising from the lack of regulation of the enzymes is the immediate capacity to catabolise and use amino acids as a source of energy and for gluconeogenesis. During starvation, because of their normal highprotein diet, carnivores in general are better able to maintain glucose concentration in the blood than omnivorous animals (Kettelhut et al. 1980).

As cats do not control the activities of the enzymes of general amino acid degradation, it follows that other mechanisms must allow cats to metabolise high intakes of protein. Two mechanisms are proposed. First, the concentrations of amino acids in plasma increase with protein intake, but they always remain less than $1 \mathrm{~mm}$ and usually less than one-tenth (or even less for many of the essential amino acids) of the $K_{m}$ values of the enzymes initiating amino acid degradation. The $K_{m}$ values of the degradative enzymes are in the millimolar region and some (threonine, glutamine, serine and valine) even over $10 \mathrm{~mm}$ (Krebs, 1972). So when cats consume higher intakes of protein, the elevated amino acid concentrations increase the rates of their degradation to a greater extent than that in herbivores or omnivores because of the high enzyme activities. Second, when animals are given variable protein intakes a high-protein diet leads to an increase in the weight of the liver (rat, Das \& Waterlow, 1974; pigs, Rosebrough et al. 1983; Chen et al. 1999 and cats, Park et al. 1999). Thus even if there is no change in the activity of the amino acid degradative enzyme per gram of liver, an elevated concentration of the amino acid in plasma, especially when coupled with an increase in the size of the liver, will markedly increase the rate of amino acid catabolism. In addition, when herbivorous and omnivorous animals are suddenly changed from a low- to a high-protein diet there is a transient increase in the concentration of the amino acids in plasma and a decrease in food intake until plasma amino acids are normalised (Anderson et al. 1968). 
The limited ability of cats to control the amino acid degradative enzymes results in a higher rate of loss of $\mathrm{N}$ than occurs in omnivorous species when given a protein-free diet. Hendriks et al. (1997) reported an endogenous urinary N (EUN) loss of $360 \mathrm{mg} . \mathrm{kg}$ body weight $^{-0 \cdot 75}$ per $\mathrm{d}$ in adult cats. This value is much greater than the values reported for other species (mg N.kg body weight ${ }^{-0 \cdot 75}$ per d): dogs 210 , pigs 163 , rats 128 , marmosets 110 , man 62. A factor contributing to the higher EUN loss of cats was a higher excretion of urea $\mathrm{N}$, which contributed 0.68 of the EUN in cats but only $0.55,0.43,0.47$ of the total EUN in dogs, pigs and rats respectively. Similar differences in $\mathrm{N}$ loss between cats and other species on food deprivation regimens were reported by Biourge et al. (1994). These authors reported that obese cats lost $297 \mathrm{mg} \mathrm{N} . \mathrm{kg}$ body weight ${ }^{-2 / 3}$ per d when cats were food-deprived compared with obese human subjects (in two studies of 210 and $156 \mathrm{mg} \mathrm{N} . \mathrm{kg}$ body weight ${ }^{-2 / 3}$ per d) and obese rats (167 $\mathrm{mg} \mathrm{N.kg}$ body weight ${ }^{-2 / 3}$ per d).

\section{Arginine}

In our experiments (Rogers \& Morris, 1979) to determine the essential amino acids for growing kittens, all the $\mathrm{N}$ was supplied as free amino acids. Individual amino acids under study were removed from the diet and the performance of the kittens compared with kittens given an identical diet that contained the amino acid. For all diets (with one exception), when an essential amino acid was deleted, the food intake declined by the second day and there was a progressive slow body weight loss, but no other acute clinical signs. However, when arginine was deleted from the diet, there was a rapid overnight loss of body weight that continued over the next few days (Morris et al. 1979).

For many mammals, such as young and adult human subjects, adult pigs and pre-ruminant lambs, arginine is not an essential amino acid in the diet. The endogenous rate of synthesis is commensurate with the needs of these animals. Initially, it had been assumed in these animals that the endogenously synthesised arginine came from the urea cycle in the liver (Drotman \& Freedland, 1972). However, because of the high activity of hepatic cytosolic arginase (enzyme that catalyses the degradation of arginine to ornithine and urea), virtually none of the arginine synthesised in the liver escaped to the peripheral tissues (Featherston et al. 1973). In those animals that are independent of dietary arginine, it is produced through the combined interaction of the intestine and kidneys. Glutamate and glutamine are metabolised in the intestinal mucosa producing citrulline (Windmueller \& Spaeth, 1974, 1975; Windmueller, 1980). A key intermediate in this pathway is pyrroline-5-carboxylate (P-5-C) synthesised in the mitochondria from glutamate (Wakabayashi \& Jones, 1983; Wakabayashi et al. 1983). Citrulline produced in the intestine is converted to arginine in the kidneys, as arginase activity in the kidney is low compared with the liver (Featherston et al. 1973). The pathway of citrulline synthesis in the mitochondria of the intestinal mucosa is given in Fig. 1.

For young growing rats the rate of endogenous synthesis of arginine is sub-optimal for maximal growth and supplementation with dietary arginine enhances growth rate. Rats receiving an arginine-free diet exhibit no overt clinical signs of arginine deficiency other than decreased growth rate. In contrast, when growing kittens were food-deprived overnight and then consumed an arginine-free meal, a life-threatening situation occurred. Kittens exhibited progressive clinical signs of salivation, neurological changes, hyperaesthaesia, emesis, coma, tetany and death within an hour of consumption of as little as $5 \mathrm{~g}$ of a complete diet devoid of arginine (Morris \& Rogers, 1978a,b). These clinical signs were compatible with those of hyperammonaemia in other species, and the plasma from kittens showed that the degree of hyperam- 


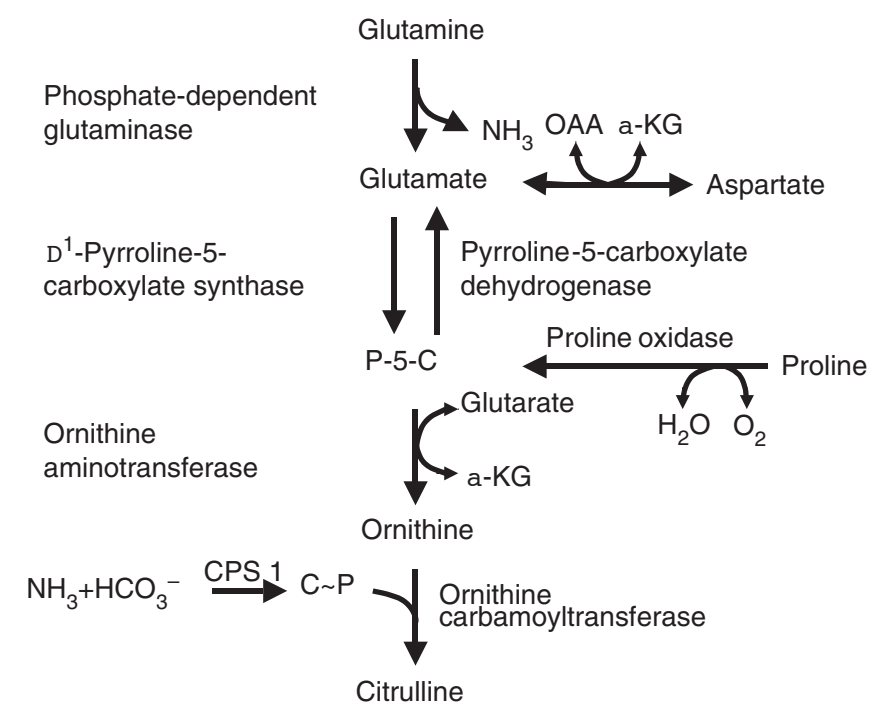

Fig. 1. Pathway of synthesis of citrulline in intestinal mucosal mitochondria of species capable of supplying their arginine requirements de novo. The activities of the enzymes pyrroline-5-carboxylate $(P-5-C)$ synthase and ornithine aminotransferase in the intestinal mucosa of cats are low, which precludes effective synthesis of citrulline. OAA, oxaloacetate; $\alpha-K G$, $\alpha$-ketoglutarate; CPS1, carbamoyl phosphate synthetase 1; C P, carbamoyl phosphate. (Adapted from Wu et al. 1997.)

monaemia was related to the severity of the clinical signs. In addition, there was a marked decrease in the concentration of arginine in plasma, and hyperglycaemia, a secondary clinical sign of hyperammonaemia, was present.

Was the hyperammonaemia a result of increased production of ammonia or decreased disposal of ammonia or both? Amino acids ingested after overnight food deprivation are rapidly deaminated as a source of energy (facilitated by the high activity of the amino acid catabolic enzymes) resulting in an increase in ammonia production. In other animals, this ammonia is converted into urea. However, overnight food deprivation in cats results in a decreased concentration of plasma arginine and the other urea cycle intermediates. Presumably the liver is also depleted of urea cycle intermediates, leading to a reduction in the rate of ammonia removal. When cats ingest a meal containing all the essential amino acids, which includes arginine, this arginine has an anaplerotic effect on the urea cycle, and facilitates disposal of the ammonia from deaminated amino acids. Depletion of the urea cycle intermediates during the post-absorption state limits urea synthesis, despite the high activities of the urea cycle enzymes. This in turn helps conserve $\mathrm{N}$ that can be used for dispensable amino acid synthesis during lengthy inter-meal intervals. Human subjects who ingest an arginine-free diet even after an overnight fast do not experience a rise in plasma ammonia concentration because endogenous synthesis can provide the intermediates for the urea cycle (Carey et al. 1987).

The activities of two enzymes in the intestinal pathway of citrulline synthesis were found to be markedly lower in cats than in rats. Costello et al. (1980) demonstrated that the activity of ornithine aminotransferase, which catalyses the transfer of an amino group to P-5-C to produce ornithine, was low in cats. Rogers \& Phang (1985) later reported that the activity of $\Delta^{1}-\mathrm{P}-5-\mathrm{C}$ synthase (a bifunctional ATP and NADPH enzyme that catalyses the reduction of glutamate to P-5-C) was only $5 \%$ on a body-weight basis of that in rats. As previously indicated, rats do not synthesise adequate arginine for maximal growth. The low activities of these two enzymes in 
cats have a multiplicative effect and result in negligible production of citrulline in the intestine, rendering cats totally dependent on dietary arginine. Chicks, like cats, are dependent on a dietary source of arginine, and ornithine will not substitute for arginine in the diet. Wu et al. (1995) reported no activity of P-5-C synthase or ornithine carbamoyltransferase in the intestinal enterocytes of chicks, which explains the inability of ornithine to replace arginine or proline in the diet. Activity of ornithine aminotransferase in chick intestinal enterocytes was also low (3 $\%$ of that in pig enterocytes) which would also be an impediment for the synthesis of ornithine from glutamate.

While the liver is the only organ that contains high activities of all the urea cycle enzymes and is normally regarded as the sole organ of urea synthesis in mammals, Davis \& Wu (1998) demonstrated that the enterocytes of pigs contain all the enzymes for the synthesis of urea. However, low activities of arginosuccinate synthetase and lyase enzymes limit the synthesis of urea. While the enterocytes in pigs may provide some defence against ammonia toxicity arising from the degradation of glutamine, this line of defence is absent in cats.

Kittens given an arginine-free diet supplemented with citrulline did not develop hyperammonaemia, and had normal growth rates because citrulline supplied urea cycle intermediates and was converted to arginine in the kidneys (Morris et al. 1979). Similarly, when ornithine was substituted for arginine in the diet, cats did not develop hyperammonaemia, but they did not grow. While ornithine had an anaplerotic effect in the urea cycle and facilitated ammonia removal, there must be an insignificant conversion of ornithine to citrulline in the peripheral tissues, which could provide arginine for growth. Ornithine has not been able to substitute for arginine in any species. Even in young pigs that have a dietary requirement for arginine, ornithine when given at four times the molar concentration of arginine in the diet did not elicit a growth response (Edmonds et al. 1987). The low rate of conversion of ornithine to citrulline could be related to a high proportion being degraded in the liver, which is first exposed to ornithine that is absorbed by the viscera. However, the main reason for ornithine being an ineffective precursor appears to be the low rate of its conversion to citrulline in the intestinal mitochondrion, a reflection of the low activity of ornithine transcarbamoylase (Fig. 1). There is extensive metabolism of amino acids, especially glutamine, of both dietary and systemic origin in the intestinal mucosa resulting in the production of ammonia.

Most natural proteins contain sufficient arginine to prevent hyperammonaemia in cats. However, cats given a diet in which casein was the sole protein source developed hyperammonaemia and exhibited emesis. A 50:50 mixture of isolated soya protein and casein provides sufficient arginine to prevent hyperammonaemia.

A rationale can be advanced for the maintenance of high activities and lack of control of the catabolising enzymes of the dispensable amino acids and urea cycle enzymes in cats. Cats need to be metabolically capable, even after a prolonged fast, of handling a high-protein meal. Activities of these enzymes need to be maintained at a high level for rapid gluconeogenesis and ammonia disposal. Animal tissues provide plenty of arginine, providing arginine to the liver and urea cycle. While cats consume only animal tissue, there is no risk of hyperammonaemia, and no selection pressure to maintain citrulline synthesis. Reduced synthesis of these redundant enzymes conserves energy for cats. Stoll et al. (1999) estimated that the contribution of the portal-drained viscera to the total energy expenditure of piglets was $16 \%$. Within the order Carnivora, cats are more sensitive than dogs and ferrets to hyperammonaemia resulting from consumption of an arginine-free diet. Cats are exquisitely sensitive to arginine deficiency, for there is no other example in a mammalian species where consumption of a single meal lacking an essential nutrient can lead to death. 


\section{Taurine}

One of the first workers to attempt studies on the nutrition of cats using purified diets was Patricia Scott. Scott et al. (1964) reported that cats given a diet based on casein developed progressive retinal degeneration, which was not corrected by the addition of vitamin A to the diet. However, cats reared on a meat-based diet were normal. Later, Hayes et al. (1975) reported that a dietary deficiency of taurine produced feline central retinal degeneration. Besides the effects of a deficiency of taurine on the retina, Sturman et al. (1987) showed that there was impairment of reproduction in queens and developmental defects in kittens. Pion et al. (1987) further demonstrated that taurine deficiency was associated with dilated cardiomyopathy in cats and that the condition could be reversed by supplemental taurine.

Why are cats sensitive to taurine deficiency when taurine is not considered an essential dietary nutrient for mammals, except for human infants? Taurine is a $\beta$-sulphonic amino acid that is not a constituent of polypeptides, but occurs as a free amino acid in animal tissues. Taurine is not oxidised by mammals, but is used as a conjugate for the bile acids. Cats and dogs obligatorily use taurine to conjugate bile acids, whereas many other animals, including man, can use either glycine or taurine for bile acid conjugation. In bovines, the hepatic cholylCoA-amino acid $\mathrm{N}$-acyl transferase enzyme is capable of conjugating CoA adducts of bile acids to both glycine and taurine (Vessey, 1979). However, the affinities of the enzyme for taurine and for glycine depend on species (Vessey, 1978) and in dogs (Czuba \& Vessey, 1981), and presumably cats, the enzyme has a low affinity for glycine. That is, the enzyme resembles the non-mammalian form and synthesises only taurine conjugates. For rats, which preferentially use taurine as a conjugate, the amidation of choloyl-CoA have $K_{m}$ values for taurine of $0.9 \times$ $10^{-3} \mathrm{M}$ and for glycine of $17 \times 10^{-3} \mathrm{M}$ (Kase \& Bjorkhem, 1989). Taurine-depleted cats, unlike taurine-replete rats and man, produce a bile that contains free bile acids along with very low concentrations of glycocholate (Hickman et al. 1992).

Mammals synthesise taurine by the oxidation of the $S$ amino acid cysteine (Fig. 2). For rats, the activity of cysteine dioxygenase increases with the concentration of $\mathrm{S}$ amino acids in the diet (Stipanuk et al. 1994). Cats possess the enzymes of the pathway for taurine synthesis, but the activities of two enzymes in the pathway, cysteine dioxygenase (catalyses the oxidation of cysteine to cysteinesulphinic acid ) and cysteinesulphinic acid decarboxylase (catalyses the conversion of cysteinesulphinic acid to hypotaurine), are low. When the activities of two enzymes in a pathway are greatly reduced (as in this example and in citrulline synthesis) there is a multiplicative effect and the traffic along the pathway becomes insignificant. Most of the $S$ amino acid catabolism in cats is not along the cysteinesulphinic acid pathway. Park et al. (1999) demonstrated that in cat liver cysteine desulphydration occurs along two pathways. More than $80 \%$ of the cysteine is metabolised by the direct desulphydration pathway, and less than $20 \%$ is metabolised by the transamination pathway. The desulphydration pathway is catalysed by cysteinedesulphydrase that releases the amino group of cysteine as ammonia, whereas the transamination pathway is catalysed by cysteine aminotransferase coupled with $\beta$-mercaptopyruvate sulphurtransferase and transfers the amino group to $\alpha$-ketoglutarate. Both pathways produce pyruvate from cysteine, which may be oxidised as a source of energy.

The low enzyme activities of the synthetic pathway limit the endogenous synthesis of taurine, but it is the combination with the extremely low affinity in cats of the cholyl-CoA-amino acid $\mathrm{N}$-acyltransferase for glycine that results in the depletion of the body taurine pool. We have found that the recovery of taurine by the enterohepatic circulation is a function of the diet, particularly the protein component. Diets that contain a high percentage of indigestible protein increase cholecystokinin secretion and favour a flora that degrades taurine (Morris et al. 1994). Therefore, the dietary requirement for taurine is not fixed, but depends on the dietary ingredi- 


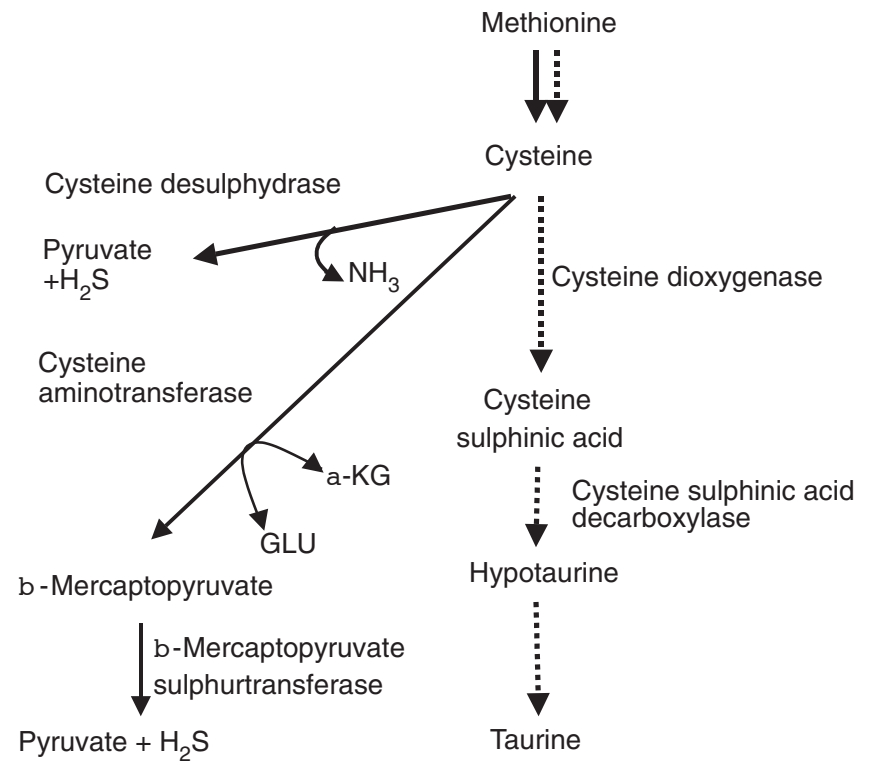

Fig. 2. General pathway of taurine synthesis in the liver from sulphur amino acids $(\cdots \rightarrow)$. The activities of the enzymes cysteine dioxygenase and cysteinesulphinic acid decarboxylase are low in cats, which severely restricts synthesis of taurine. Cysteine is largely metabolised to pyruvate, which provides an energy substrate whereas taurine cannot be oxidised by cats. $\alpha-\mathrm{KG}, \alpha$-ketoglutarate; GLU, glutamate.

ents and the method by which they are processed. This factor has special significance in preparation of commercial diets for cats, as canned diets need about twice the concentration of taurine as expanded diets to maintain normal taurine concentrations in plasma. Taurine is well supplied in animal tissue but may become limiting in diets of animal tissue to which significant amounts of vegetable matter have been added and in diets where processing has resulted in Maillard products, which enhance microbial degradation of taurine in the gut.

In the wild, cats had a diet of small mammals and birds and consumed the whole body, which provided adequate taurine to meet the body needs without synthesis. Under these conditions it is energetically advantageous for cats to use pathways of cysteine catabolism that produce a substrate (pyruvate) that can be oxidised as a source of energy. For cats consuming adequate taurine in the diet, no benefit is derived from the conversion of cysteine to taurine to be excreted in the urine, and there is a loss of potential energy in the process.

\section{Vitamins}

The dietary requirements of cats for certain of the vitamins differ both qualitatively and quantitatively from those of most other mammals. These peculiarities can be related to differences in enzyme activities in the pathways of synthesis of vitamins A, D and niacin.

\section{Vitamin A}

The inability of cats to use carotenoids as a source of vitamin A was one of the first nutritional peculiarities of cats that was identified (Gershoff et al. 1957). It appears that cats cannot under- 
take either the symmetrical or the asymmetrical cleavage of the carotene molecule, the first step in the conversion of carotenoids to retinal. The enzyme responsible for symmetrical cleavage of $\beta$-carotene has been known for more than 40 years, but it had never been isolated from any species or characterised. Recently the gene for $\beta, \beta$-carotene 15,15 '-dioxygenase was cloned from chickens (Wyss et al. 2000) and the homology between chicken and mouse sequences was found to be $81 \%$ (Wyss et al. 2001). While this enzyme is evolutionarily rather well conserved across these species, in cats it appears to have been deleted from the normal tissue sites of the duodenal villi, liver, and tubular structures of the lung and kidney. As animal tissue contains only low concentrations of carotenoids, the ability of cats to produce retinal from carotenoids is redundant, and maintenance of this enzyme or the asymmetric cleavage enzyme would be an unwarranted energetic cost.

Another peculiarity of vitamin A metabolism that cats share with some of the other carnivores is the high level of retinyl esters (predominately retinyl stearate and palmitate) in the plasma. In man and rats, almost all the vitamin A in plasma is combined with retinol-binding protein, and esters are present in significant concentrations only when toxic levels of vitamin A are ingested.

As many commercial cat foods, particularly canned foods in the United States, contain appreciable amounts of liver, and as much of this liver comes from pigs (receiving diets high in vitamin A) we investigated the potential for vitamin A toxicity in adult cats. Seawright et al. (1970) demonstrated that excessive intakes of vitamin A in growing kittens given a diet of liver led to the formation of exostoses on the cervical vertebrae. Our approach was to examine the effects of long-term excess dietary vitamin A (306 and $606 \mathrm{mg}$ retinol equivalents (RE), i.e. 1 and 2 million IU of vitamin $\mathrm{A} / \mathrm{kg}$ diet) on teratology. Over a 3-year period and multiple pregnancies, total fatal and non-fatal malformation rates in the kittens born to queens from the control (6 mg RE), $306 \mathrm{mg} \mathrm{RE}$ and $606 \mathrm{mg} \mathrm{RE}$ groups were: fatal 1.5, 1.6 and 9.1\% respectively, and non-fatal; $0,1 \cdot 1$ and $5 \cdot 2 \%$ respectively (Freytag, 2001). While there is a significant increase in malformation rates with high intakes of vitamin A, these rates are low compared with other species. When compared with rats (the most tolerant other species tested to date) given a similar dose only during gestation, the incidence of a specific malformation (cleft palates) in the offspring was $80 \%$ compared with $2.9 \%$ in kittens from queens in the $606 \mathrm{mg}$ RE group. There were no apparent deleterious effects of the high intakes of vitamin $\mathrm{A}$ on the queens (Freytag, 2001). Cats given high dietary intakes of vitamin A excreted large amounts of conjugates in the urine and, while liver stores of vitamin A progressively increased over a 3year period, there were minimal signs of toxicity.

Evolutionary pressures may have rendered cats more tolerant than other species to excess vitamin A in the diet. As cats use only pre-formed retinyl esters, they lack control over the conversion of carotenoids to retinal, which is one of the controls that prevents toxicity in other animals that utilise carotenoids. An all-animal tissue diet could potentially expose cats to high retinyl ester loads, especially if they exhibited a predilection for viscera. High retinyl ester loads may have induced an enhanced capacity in cats for retinyl conjugation and excretion. The studies of Freytag (2001) support this conclusion, as cats given radiolabelled retinol excreted large quantities of an unidentified polar conjugate in urine that is not present in the urine of other animals.

\section{Vitamin D}

For most animals, vitamin D is a conditionally essential nutrient as normal exposure to sunlight negates a dietary requirement. While cats are covered with hair, which would impede u.v. light 
reaching the skin, the propensity for cats to lie in the sun and expose their ventral abdomens (which have less hair than the rest of the body) suggested that cats might synthesise vitamin D. Sheep synthesise vitamin D on exposed parts of the body, despite their heavy pelage. However, kittens, both shaved and unshaved, exposed to direct sunlight were found not to be able to synthesise vitamin D (Morris, 1999). Cat skin contains a low concentration of 7-dehydrocholesterol, the precursor for pre-vitamin D (How et al. 1994; Morris, 1999). However, when vitamin D-deficient kittens were exposed to u.v. light and given a diet containing an inhibitor of the enzyme 7-dehydrocholesterol- $\Delta^{7}$-reductase (which catalyses the conversion of 7-dehydrocholesterol to cholesterol), the concentration of 7-dehydrocholesterol in skin was greatly augmented. Also, the concentrations of 25-hydroxyvitamin D in the plasma of these kittens increased to normal levels, indicating synthesis of vitamin D. Similar kittens exposed to u.v. light without the inhibitor in their diet, maintained low levels of 7-dehydrocholesterol in skin and deficient plasma levels of 25-hydroxyvitamin D.

How do cats in the wild obtain their vitamin D if they are unable to undertake endogenous synthesis? The vitamin D requirement of growing kittens is similar to that of other animals (Morris et al. 1999). Analyses of the vitamin D concentration of potential prey of cats (rodents and birds) indicated that the prey could provide adequate amounts of the vitamin without the need for endogenous synthesis. The cat's obligatory dietary requirement for vitamin D is an example where synthesis is prevented by the high activity of an enzyme that reduces the availability of the precursor substrate.

Cats appear to be more tolerant to excess vitamin D in the diet than other mammals (Sih et al. 2001). The possible reasons for this tolerance have not been investigated. Retinoic acid and 1,25 dihydroxyvitamin $\mathrm{D}$ use specific nuclear receptors that are members of the steroid superfamily of ligand-activated transcription factors, which may provide a common link for the cat's tolerance to excesses of both vitamins.

\section{Niacin}

For most species, the niacin equivalence of foods is the sum of nicotinamides in the food and the potential endogenous nicotinic acid synthesised from tryptophan. The molar yield of nicotinic acid from tryptophan varies with species, but is of the order of 33 to 40 and $60 \mathrm{mg}$ tryptophan/mg of niacin synthesised in rats and man respectively (Hankes et al. 1948; Horwitt et al. 1956). The extent of conversion of tryptophan to nicotinic acid is determined by the fate of $\alpha-$ amino- $\beta$-carboxymuconic- $\varepsilon$-semialdehyde, an intermediate in the pathway of tryptophan metabolism, which can be metabolised by either of two pathways. One results in the production of acetyl $\mathrm{CoA}$ and $\mathrm{CO}_{2}$ and the other to NAD. Picolinic carboxylase is the enzyme catalysing the first step of the degradative pathway to acetyl $\mathrm{CoA}$ and $\mathrm{CO}_{2}$ and across species the dietary niacin requirement is inversely related to the hepatic activity of this enzyme (Ikeda et al. 1965; Scott, 1986). Cats possess all the enzymes of the pathway of niacin synthesis, but the activity of picolinic carboxylase is extremely high, the highest of all animals studied (Sudadolnik et al. 1957; Ikeda et al. 1965), precluding any measurable synthesis of nicotinic acid (Da Silva et al. 1952; Leklem et al. 1969). Meat is well supplied with the NAD and NADP coenzymes, and while cats consume a diet of animal tissue there is no need to produce niacin from tryptophan. The direct production of acetyl CoA may be energetically more efficient for cats than the oxidation NAD or the intermediates of the NAD pathway.

The absolute requirements of niacin and vitamin $\mathrm{D}$ by cats are examples of high activities of enzymes reducing the availability of the precursors required for synthesis of the vitamins. 


\section{Coat colour in cats}

Tyrosine is not an essential amino acid for growing kittens (Rogers \& Morris, 1979), but tyrosine can supply about half of the total aromatic amino acid requirement of kittens (Williams et al. 1987). Tyrosine is the precursor of 3,4-dihydroxyphenylalanine and melanins, the pigments of hair and skin. The colour of mammalian hair is dependent on the amount and type of melanin present. Two forms of melanin occur in hair as co-polymers: cysteine-containing pheomelanin, which is reddish brown, and eumelanin, which is black-brown in colour (Ito et al. 1993; Ozeki et al. 1997). Black hair is high in eumelanin, and hair in which pheomelanin predominates has a reddish colour. The pathway of synthesis of these melanins from tyrosine has been presented by Morris et al. (2002). $\mathrm{Cu}$, which is an integral part of tyrosinase, a key enzyme in melanin synthesis, is probably the best-known example where a single nutrient deficiency in many species results in a change in hair colour. Although less often quoted, the nutritional states in man of kwashiorkor and phenylketonuria are associated with changes, or loss of hair colour.

Yu et al. (2001) demonstrated that the maintenance of hair colour in cats is dependent on the quantity of phenylalanine plus tyrosine in the diet, and the critical concentration has been reported to be about $18 \mathrm{~g}$ phenylalanine + tyrosine $/ \mathrm{kg}$ diet (Anderson et al. 2002). As phenylalanine is obligatorily metabolised to tyrosine, the sum of both amino acids is used to estimate the potential tyrosine available for melanin synthesis. The total aromatic amino acid requirement of kittens that supported maximal growth and $\mathrm{N}$ balance in short-term experiments reported by Williams et al. (1987) and used by the National Research Council (1986) was $8.5 \mathrm{~g}$ phenylalanine + tyrosine $(4 \cdot 0 \mathrm{~g}$ phenylalanine $+4 \cdot 5 \mathrm{~g}$ tyrosine $) / \mathrm{kg}$ diet, a requirement less than half that for the maximum expression of coat colour. This large difference appears to be due to the $K_{m}$ of the enzymes involved in eumelanin synthesis for tyrosine being very much higher than the $K_{m}$ of those involved in tissue growth. There are other examples of nutrients (for example, histidine) where the requirement of cats is dependent on the criterion used (Quam et al. 1987). However, we are unaware of a requirement for a secondary function in any animal being so much greater than the requirement for growth.

The wild-type hair colour pattern of cats is alternate black and grey stripes in a mackerel pattern that presumably provides camouflage for cats while hunting. A diet of all animal tissue would provide levels of aromatic amino acids sufficient to support full development of hair colour.

\section{Other nutrient peculiarities of cats}

\section{Essential fatty acids}

There is consensus that cats, in common with all other mammals, require linoleate in the diet and a source of $n-3$ fatty acids. But, the exact requirements of cats for long-chain polyunsaturated fatty acids is not clear. There is also consensus that cats have a limited capacity to synthesise arachidonate from linoleate, and probably eicosapentaenoate and docosahexaenoate from $\alpha$-linolenate (MacDonald et al. 1983; Bauer, 1997). This limited synthetic capacity was attributed to low desaturase activities of cat liver (Rivers et al. 1975; Sinclair et al. 1979) and it was assumed that the diet of cats had to contain a source of animal fat to supply arachidonate. Subsequently, the essentiality of arachidonate was questioned when McLean \& Monger (1989) demonstrated that queens given an all-vegetable-fat diet could produce up to two litters of kittens. Pawlosky et al. (1994) demonstrated that cats possess low $\Delta 6$-desaturase activity and are capable of limited synthesis of arachidonate. This group later demonstrated that reproduction 
was supported in queens given an arachidonate-free diet containing $7 \mathrm{~g}$ linoleic acid/ $\mathrm{kg}$ diet, contributed by $30 \mathrm{~g}$ maize oil/kg diet (Pawlosky \& Salem, 1996). Lower concentrations (0·087 $\mathrm{g} / \mathrm{kg}$ diet) of linoleate in the diet were inadequate for reproduction. In another experiment, Pawlosky et al. (1997) found that maize-oil-based diets were capable of maintaining the arachidonate $(20: 4 n-6)$ concentration in the developing brain of kittens, but only those diets containing docosahexaenoic acid (22:6n-3) could support a high accumulation of $22: 6 n-3$ in the brain. Retinograms of 8 -week-old kittens raised in litters in which the maternal diets were devoid of arachidonate and docosahexaenoate had increased $\mathrm{a}$ and $\mathrm{b}$ wave-implicit times compared with control kittens from queens that received both $20: 4 n-6$ and $22: 6 n-3$ in the diet. Low concentrations of $22: 5 n-6$ were found in the brains of kittens whose dams received the maize-oil diets. The studies indicate that in juvenile felines the maintenance of $22: 6 n-3$ status in the nervous system is important for optimal retinal function and further support the low synthetic capacity of cats to produce $22: 6 n-3$.

Reproduction in male cats appears normal when given an all-vegetable-fat diet devoid of arachidonate (MacDonald et al. 1984; JG Morris, unpublished results). The testes of toms receiving a linoleate-containing diet had higher levels of arachidonate (indicating synthesis) than in the testes of cats given a linoleate-free diet. No studies on the quantitative requirement of cats for long-chain $n-3$ fatty acids have been made.

\section{Carbohydrate utilisation}

Mammals possess up to four isoenzymes in the liver that catalyse the formation of glucose- 6 phosphate from glucose. All four are present in rat liver, but many mammals have only two or three isozymes. Ureta (1982) reported seven chromatographic patterns of liver hexokinases from mammals. The major hexokinase in most animals is hexokinase D or type IV often referred to as glucokinase. Glucokinase is not present in the liver of cats (Ballard, 1965; Ureta, 1982; Washizu et al. 1999), which is consistent with a low glucose load from an all-animaltissue diet. The chromatographic pattern of cat liver exhibits two hexokinases and more closely resembles the ruminant profile, which also has two hexokinases, than other mammals. In contrast, dog livers have three hexokinases that include hexokinase D. Similarly, canine leucocytes contain glucokinase, which is absent in feline leucocytes (Arai et al. 1998), but the activity of hexokinase is higher in feline than canine leucocytes.

While cats have a lower pancreatic amylase activity than dogs or pigs (Kienzle, 1993a), they can efficiently digest cooked starch in the diet (Morris et al. 1977; Kienzle, 1993b). Dietary glucose appears to be efficiently utilised by cats, but cats have only a limited capacity to use sucrose. High intakes of sucrose result in fructosaemia and fructosuria (Drochner \& Müller-Schlösser, 1980). Whether this condition is due to a deficiency of fructokinase and similar to the inborn error of metabolism in man (Hommes, 1993) has not been examined. While fructose can be metabolised in the absence of fructokinase by hexokinase, the $K_{m}$ values of hexokinase for fructose and glucose are $1.5 \times 10^{-3} \mathrm{~mm}$ and $8 \times 10^{-6} \mathrm{~mm}$ respectively (Crane \& Sols, 1955). Thus the rate of phosphorylation of fructose at a concentration of $1 \mathrm{~mm}$ in the presence of a normal blood glucose concentration of $5 \mathrm{~mm}$ in a cat will be very slow in the absence of fructokinase.

Cats have an abridged pattern of carbohydrate metabolising enzymes compared with many omnivores. The deletion of enzymes required for metabolising high carbohydrate loads and fruit sugar does not compromise cats, as long as they consume a diet of animal tissue, and conserves energy required for their synthesis. 


\section{Conclusions}

The present overview of the idiosyncratic nutritional requirements of domestic cats updates an earlier review (Morris \& Rogers, 1982) and attempts to link the dietary essentiality of these nutrients to differences in the activities of key enzymes. The limited ability of cats to control the aminotransferases and urea cycle enzymes explains the high protein requirement of cats. The observations that other carnivorous animals including fish and birds also have limited control of the aminotransferases suggests that this confers some advantage to these animals. As this adaptation has occurred in unrelated genera it is an example of comparative evolution.

The essentiality of five nutrients in the diet of cats, but not in the diet of most other animals, results from limited or total lack of synthesis of these nutrients. Two of these nutrients are amino acids (arginine and taurine), whose essentiality can be related to low activities of two enzymes in each pathway of synthesis. The other three nutrients are vitamins. In the case of niacin and vitamin $\mathrm{D}$, high activities of enzymes result in degradation of the precursors for their synthesis. The third vitamin (vitamin A) has to be present pre-formed in the diet rather than supplied as carotenoids because of the complete deletion of an enzyme required for the oxidation of carotene to retinal. These nutrients do not become limiting to cats that consume an allanimal-tissue diet. It is suggested that evolutionary pressures have resulted in deletion or modulation of these enzymes to provide metabolites more suited to the needs of cats. The modulation has also occurred in the enzymes of carbohydrate metabolism.

\section{References}

Alexis MN \& Papaparaskeva-Papoutsoglou E (1986) Aminotransferase activity in the liver and white muscle of Mugil capito fed diets containing different levels of protein and carbohydrate. Comparative Biochemistry and Physiology 83B, 245-249.

Anderson HL, Benevenga NJ \& Harper AE (1968) Associations among food and protein intake, serine dehydratase, and plasma amino acids. American Journal of Physiology 214, 1008-1013.

Anderson PJB, Rogers QR \& Morris JG (2002) Cats require higher dietary phenylalanine or tyrosine for melanin in hair than growth. Journal of Nutrition 132 (In the Press).

Arai T, Kawaue T, Abe M, Kuramoto E, Kamakami E, Sako T \& Washizu T (1998) Comparison of glucokinase activities in the peripheral leukocytes between dogs and cats. Comparative Biochemistry and Physiology 120C, 53-56.

Baker DH \& Speer VC (1983) Protein-amino acid nutrition of nonruminant animals with emphasis on the pig: past, present and future. Journal of Animal Science 57, Suppl. 2, 248-299.

Ballard FJ (1965) Glucose utilization in the mammalian liver. Comparative Biochemistry and Physiology 14, $437-443$.

Bauer JE (1997) Fatty acid metabolism in domestic cats (Felis catus) and cheetahs (Acinonyx jubatas). Proceedings of the Nutrition Society 56, 1013-1024.

Biourge V, Groff JM, Fisher C, Bee D, Morris JG \& Rogers QR (1994) Nitrogen balance, plasma free amino acid concentrations and urinary orotic acid excretion during long-term fasting in cats. Journal of Nutrition 124, 1094-1103.

Carey GP, Kime Z, Rogers QR, Morris JG, Hargrove D, Buffington CA \& Brusilow SW (1987) An arginine-deficient diet in humans does not evoke hyperammonaemia or orotic aciduria. Journal of Nutrition 117, 1734-1739.

Chandra M, Singh B, Soni GL \& Ahuja SP (1984) Renal and biochemical changes produced in broilers by high-protein, high-calcium, urea-containing, and vitamin A-deficient diets. Avian Diseases 28, 1-11.

Chen HY, Lewis AJ, Miller PS \& Yen JT (1999) The effect of excess protein on growth performance and protein metabolism of finishing barrows and gilts. Journal of Animal Science 77, 3238-3247.

Costello MJ, Morris JG \& Rogers QR (1980) Effect of dietary arginine level on urinary orotate and citrate excretion in growing kittens. Journal of Nutrition 110,1204-1208.

Coulson RA \& Hernandez T (1983) Alligator Metabolism. Studies on Chemical Reactions In Vivo. Oxford, UK: Pergamon Press.

Cowey CB, Cooke DJ, Matty AJ \& Adron JW (1981) Effects of quantity and quality of dietary protein on certain enzyme activities of rainbow trout. Journal of Nutrition 111, 336-345.

Crane RK \& Sols A (1955) Animal tissue hexokinases. Methods in Enzymology 1, 277-286.

Czuba B \& Vessey DA (1981) Identification of a unique mammalian species of cholyl-CoA: amino acid N-acyltransferase. Biochimica Biophysica Acta $\mathbf{6 6 5}, 612-614$.

Das TK \& Waterlow JC (1974) The rate of adaptation of the urea cycle enzymes, aminotransferases and glutamic dehydrogenase to changes in dietary protein. British Journal of Nutrition 32, 353-373. 
Da Silva AC, Fried R \& De Angelis RC (1952) The domestic cat as a laboratory animal for experimental nutrition studies. Journal of Nutrition 46, 399-409.

Davis PK \& Wu G (1998) Compartmentation and kinetics of urea cycle enzymes in porcine enterocytes. Comparative Biochemistry and Physiology 119B, 527-537.

Drochner W \& Müller-Schlösser S (1980) Digestibility and tolerance of various sugars in cats. In Nutrition of the Dog and Cats, pp. 101-111 [RS Anderson, editor] Oxford: Pergamon Press.

Drotman RB \& Freedland RA (1972) Citrulline metabolism in the perfused rat liver. American Journal of Physiology 222, 973-975.

Edmonds MS \& Baker DL (1987) Effects of fasting on tissue amino acid concentrations and urea-cycle enzymatic activities in young pigs. Journal of Animal Science 65, 1538-1552.

Edmonds MS, Lowry KR \& Baker DH (1987) Urea cycle metabolism: effects of supplemental ornithine or citrulline on performance, tissue amino acid concentrations and enzymatic activity in young pigs fed arginine-deficient diets. Journal of Animal Science 65, 706-716.

Featherston WR \& Freedland RA (1973) Influence of dietary protein and carbohydrate levels on liver enzyme activities in quail. Journal of Nutrition 103, 625-634.

Featherston WR, Rogers QR \& Freedland RA (1973) Relative importance of kidney and liver in synthesis of arginine by the rat. American Journal of Physiology 224, 127-129.

Freedland RA (1964) Urea cycle adaptations in intact and adrenalectomized rats. Proceedings of the Society of Experimental Biology and Medicine 116, 692-696.

Freytag TL (2001) Vitamin A metabolism and toxicity in the domestic cat. PhD Thesis, University of California, Davis.

Gershoff SN, Andrus SB, Hegsted DM \& Lentini EA (1957) Vitamin A deficiency in cats. Laboratory Investigation 6, $227-240$.

Hankes LV, Henderson LM, Brickson WL \& Elvehjem CA (1948) Effect of amino acids on growth of rats on niacintryptophan deficient rations. Journal of Biological Chemistry 174, 873-881.

Harper AE (1965) Effect of variations in protein intake on enzymes of amino acid metabolism. Canadian Journal of Biochemistry 43,1589-1603.

Hayes KC, Carey RE \& Schmidt SJ (1975) Retinal degeneration associated with taurine deficiency in the cat. Science 188, 949-951.

Hendriks WH, Moughan PJ \& Tarttelin MF (1997) Urinary excretion of endogenous nitrogen metabolites in adult domestic cats using a protein-free diet and the regression technique. Journal of Nutrition 127, 623-639.

Hickman MA, Bruss ML, Morris JG \& Rogers QR (1992) Dietary protein source (soybean vs. casein) and taurine status affect kinetics of the enterohepatic circulation of taurocholic acid in cats. Journal of Nutrition 122, 1019-1028.

Hommes FA (1993) Inborn errors of fructose metabolism. American Journal of Clinical Nutrition 58, Suppl., 788S-795S.

Horwitt MK, Harvey CC, Rothwell WS, Cutler JL \& Haffron D (1956) Tryptophan-niacin relationships in man. Journal of Nutrition 60, Suppl. 1.

How KL, Hazewinkel HAW \& Mol JA (1994) Dietary dependence of cat and dog due to inadequate cutaneous synthesis of vitamin D. General Comparative Endocrinology 96, 12-18.

Ikeda MH, Tsuji H, Nakamura S, Ichiyama A, Nishizuki Y \& Hayaishi O (1965) Studies on the biosynthesis of nicotinamide adenine dinucleotides. II. Role of picolinic carboxylase in the biosynthesis of NAD from tryptophan in mammals. Journal of Biological Chemistry 240, 1395-1401.

Ito S, Wakamatsu K \& Ozeki H (1993) Spectrophotometric assay of eumelanin in tissue samples. Analytical Biochemistry 215, 273-277.

Johnson WE \& O'Brien SJ (1997) Phylogenetic reconstruction of the Felidae using 16S RNA and NADH-5 mitochondrial genes. Journal of Molecular Evolution 44, Suppl. 1, S98-S116.

Kaplan JH \& Pitot HC (1970) Enzymatic and metabolic regulation in animals. Physiological Reviews 36, $164-254$.

Kase BF \& Bjorkhem I (1989) Peroxisomal bile acid-CoA: amino-acid N-acyltransferase in rat liver. Journal of Biological Chemistry 264, 9220-9223.

Kettelhut IC, Foss MC \& Migliorini RH (1980) Glucose homeostasis in a carnivorous animal (cat) and in rats fed a high-protein diet. American Journal of Physiology 239, R115-R121.

Kienzle E (1993a) Carbohydrate metabolism of the cat 1 . Activity of amylase in the gastrointestinal tract of the cat. Journal of Animal Physiology and Animal Nutrition 69, 92-101.

Kienzle E (1993b) Carbohydrate metabolism of the cat 2. Digestion of starch. Journal of Animal Physiology and Animal Nutrition 69, 102-114.

Koutsos EA, Smith S, Woods LW \& Klasing KC (2001) Adult cockatiels (Nymphicus hollandicus) metabolically adapt to high protein diets. Journal of Nutrition 131, 2014-2020.

Krebs HA (1972) Some aspects of the regulation of fuel supply in omnivorous animals. Advances in Enzyme Regulation 10, 397-420.

Leklem JE, Woodford J \& Brown RR (1969) Comparative tryptophan metabolism in cats and rats. Differences in adaptation of tryptophan oxygenase and in vivo metabolism of tryptophan, kynurenine and hydroxykynurenine. Comparative Biochemistry and Physiology 31, 95-109.

MacDonald ML, Rogers QR \& Morris JG (1983) Role of linoleate as an essential fatty acid for the cat independent of arachidonate synthesis. Journal of Nutrition 113, 1422-1433. 
MacDonald ML, Rogers QR, Morris JG \& Cupps PT (1984) Effects of linoleate and arachidonate deficiencies on reproduction and spermatogenesis in the cat. Journal of Nutrition 114, 719-726.

McLean JG \& Monger EA (1989) Factors determining the essential fatty acid requirements of the cat. In Nutrition of the Dog and Cat, Waltham Symposium no. 7, pp. 329-342 [IH Burger and JPW Rivers, editors]. Cambridge: Cambridge University Press.

Migliorini RH, Lindner C, Moura JL \& Veiga JA (1973) Gluconeogenesis in a carnivorous bird (black vulture). American Journal of Physiology 225, 1389-1392.

Morris JG (1999) Ineffective vitamin D synthesis in cats is reversed by an inhibitor of 7-dehydrocholosterol- $\Delta^{7}$-reductase. Journal of Nutrition 129, 903-908.

Morris JG (2001) Unique nutrient requirements of cats appear to be diet-induced evolutionary adaptations. Recent Advances in Animal Nutrition in Australia 13, 187-194.

Morris JG, Earle KE \& Anderson PA (1999) Plasma 25-hydroxyvitamin D in growing kittens is related to dietary intake of cholecalciferol. Journal of Nutrition 129, 909-912.

Morris JG \& Rogers QR (1978a) Ammonia intoxication in the near-adult cat as a result of a dietary deficiency of arginine. Science 199, 431-432.

Morris JG \& Rogers QR (1978b) Arginine: an essential amino acid for the cat. Journal of Nutrition 108, $1944-1953$.

Morris JG \& Rogers QR (1982) Metabolic basis for some of the nutritional peculiarities of the cat. Journal of Small Animal Practice 23, 599-613.

Morris JG, Rogers QR, Kim SW \& Backus RC (1994) Dietary taurine requirement of cats is determined by microbial degradation of taurine in the gut. Advances in Experimental Medicine and Biology 359, 59-70.

Morris JG, Rogers QR, Winterrowd DL \& Kamikawa EM (1979) The utilization of ornithine and citrulline by the growing kitten. Journal of Nutrition 109, 724-729.

Morris JG, Trudell J \& Pencovic T (1977) Carbohydrate digestion by the domestic cat (Felis catus). British Journal of Nutrition 37, 365-373.

Morris JG, Yu S \& Rogers QR (2002) Red hair in black cats is reversed by addition of tyrosine to the diet. Journal of Nutrition 132 (In the Press).

Murphy WJ, Sun S, Chen Z, Yuhki N, Hirshmann D, Menotti-Raymond M \& O'Brien SJ (2000) A radiation hybrid map of the cat genome: implications of comparative mapping. Genome Research 10, 691-702.

Myers MR \& Klasing KC (1999) Low glucokinase activity and high rates of gluconeogenesis contribute to hyperglycemia in barn owls (Tyto alba) after a glucose challenge. Journal of Nutrition 129, 1896-1904.

National Research Council (1986) Nutrient Requirements of Cats. Washington DC: National Academy Press.

O’Brien SJ, Menotti-Raymond M, Murphy WJ, Nash WG, Weinburg J, Stanyon R, Copeland NG, Jenkins NA, Womack JE \& Marshall Graves JA (1999) The promise of comparative genomics in mammals. Science 286, $458-481$.

O’Brien SJ \& Yuhki N (1999) Comparative genome organization of the major histocompatibility complex: lessons from the Felidae. Immunological Reviews 167, 133-144.

Ozeki H, Wakamatsu K, Ito S \& Ishguro I (1997) Chemical characterization of eumelanins with special emphasis on 5, 6 dihydroxyindole-2-carboxylic acid content and molecular size. Analytical Chemistry 248, 149-157.

Park T, Rogers QR \& Morris JG (1999) High dietary protein and taurine increase cysteine desulfhydration in kittens. Journal of Nutrition 129, 2225-2230.

Pawlosky R, Barnes A \& Salem N Jr (1994) Essential fatty acid metabolism in the feline: relationship between liver and brain production of long-chain polyunsaturated fatty acids. Journal of Lipids Research 35, 2032-2040.

Pawlosky RJ, Denkins Y, Ward G \& Salem N Jr (1997) Retinal and brain accretion of long-chain polyunsaturated fatty acids in developing felines: the effects of corn oil-based maternal diets. American Journal of Clinical Nutrition $\mathbf{6 5}$, 465-472.

Pawlosky RJ \& Salem N Jr (1996) Is dietary arachidonic acid necessary for feline reproduction? Journal of Nutrition 126, 1081S-1085S.

Payne E \& Laws L (1976) The efficacy of protein supplementation in overcoming urea toxicity in sheep. British Journal of Nutrition 35, 47-54.

Payne E \& Laws L (1978) Tissue enzyme levels as indices of protein status in sheep. British Journal of Nutrition 39, 441-449.

Payne E \& Morris JG (1969) The effect of protein content of the diet on the rate of urea formation in sheep liver. Biochemical Journal 113, 659-662.

Pecon Slattery J \& O'Brien SJ (1998) Patterns of Y and X chromosome DNA sequences divergence during feline radiation. Genetics 148, 1245-1255.

Pion PD, Kittleson MD, Rogers QR \& Morris JG (1987) Myocardial failure in cats associated with low plasma taurine: a reversible cardiomyopathy. Science $\mathbf{2 3 7}, 764-768$.

Quam DD, Morris JG \& Rogers QR (1987) Histidine requirement of kittens for growth, haematopoiesis and prevention of cataracts. British Journal of Nutrition 58, 521-532.

Rivers JPW, Sinclair AJ \& Crawford MA (1975) Inability of the cat to desaturate essential fatty acids. Nature 259, $171-173$.

Rogers QR \& Morris JG (1979) Essentiality of amino acids for the growing kitten. Journal of Nutrition 109, 718-723.

Rogers QR \& Morris JG (1980) Why does the cat require a high protein diet? In Nutrition of the Dog and Cat, pp. 45-66 [RS Anderson, editor] Oxford: Pergamon Press. 
Rogers QR, Morris JG \& Freedland RA (1977) Lack of hepatic enzymatic adaptation to low and high levels of dietary protein in the adult cat. Enzyme 22, 348-356.

Rogers QR \& Phang JM (1985) Deficiency of pyrroline-5-carboxylate synthase in the intestinal mucosa of the cat. Journal of Nutrition 115, 146-150.

Rosebrough RW, Steele NC \& McMurtry JP (1983) Effect of protein level and supplemental lysine on growth and urea cycle enzyme activity in the pig. Growth $47,348-360$.

Schimke RT (1962) Adaptive characteristics of urea cycle enzymes in the rat. Journal of Biological Chemistry 237, 149-168.

Schimke RT (1963) Studies on factors affecting the levels of urea cycle enzymes in rat liver. Journal of Biological Chemistry 238, 1012-1018.

Scott ML (1986) Nutrition of Humans and Selected Animal Species, p. 225. New York: John Wiley and Sons.

Scott PP, Graves JP \& Scott MG (1964) Nutritional blindness in the cat. Experimental Eye Research 3, $357-364$.

Seawright AA, English PB \& Gartner RJW (1970) Hypervitaminosis A of the cat. Advances in Veterinary Science and Comparative Medicine 14, 1-27.

Sih TR, Morris JG \& Hickman MA (2001) Cats tolerate chronic ingestion of high levels of cholecalciferol. American Journal of Veterinary Research 62,1500-1506.

Sinclair AJ, McLean JG \& Monger EA (1979) Metabolism of linoleic acid in the cat. Lipids 14, 932-936.

Stephen JML \& Waterlow JC (1968) Effect of malnutrition on activity of two enzymes concerned with amino acid metabolism in human liver. Lancet $\mathbf{i}, 118-119$.

Stipanuk MH, Bagley PJ, Hou Y-C, Bella DL, Banks MF \& Hirschberger LL (1994) Hepatic regulation of cysteine utilization for taurine synthesis. Advances in Experimental Medicine and Biology 359, 79-89.

Stoll B, Burrin DG, Henry J, Yu H, Jahoor F \& Reeds PJ (1999) Substrate oxidation by the portal drained viscera of fed piglets. American Journal of Physiology 277, E168-E175.

Sturman JA, Palackal T, Lmaki H, Moretz RC, French J \& Wisniewski HM (1987) Nutritional taurine deficiency and feline pregnancy and outcome. Advances in Experimental Medicine and Biology 217, 113-124.

Sudadolnik RJ, Stevens CO, Dechner RH, Henderson LM \& Hankes LV (1957) Species variation in the metabolism of 3-hydroxyanthranilate to pyridinecarboxylic acids. Journal of Biological Chemistry 228, 973-982.

Ureta T (1982) The comparative isoenzymology of vertebrate hexokinases. Comparative Biochemistry and Physiology 71B, 549-555.

Vessey D (1978) The biochemical basis for the conjugation of bile salts with either glycine or taurine. Biochemical Journal 174, 621-626.

Vessey DA (1979) The co-purification and common identity of cholylCoA:glycine-and cholyl CoA:taurine-N-acyltransferase activities of bovine liver. Journal of Biological Chemistry 254, 2059-2063.

Washizu T, Tanaka A, Sako T, Washizu M \& Arai T (1999) Comparison of the activities of enzymes related to glycolysis and gluconeogenesis in the liver of dogs and cats. Research in Veterinary Science 67, 203-204.

Wakabayashi Y, Henslee JG \& Jones ME (1983) Pyrroline-5-carboxylate synthesis from glutamate by rat intestinal mucosa. Subcellular localization and temperature stability. Journal of Biological Chemistry 258, 3873-3882.

Wakabayashi Y \& Jones ME (1983) Pyrroline-5-carboxylate synthesis from glutamate by rat intestinal mucosa. Journal of Biological Chemistry 258, 3865-3872.

Williams JM, Morris JG \& Rogers QR (1987) Phenylalanine requirement of kittens and sparing effect of tyrosine. Journal of Nutrition 117, 1102-1107.

Windmueller HG (1980) Enterohepatic aspects of glutamine metabolism. In Glutamine: Metabolism, Enzymology and Regulation, chapter 13, pp. 235-237 [J Mora and R Palacios, editors]. New York: Academic Press.

Windmueller HG \& Spaeth AE (1974) Uptake and metabolism of plasma glutamine by the small intestine. Journal of Biological Chemistry 249, 5070-5079.

Windmueller HG \& Spaeth AE (1975) Intestinal metabolism of glutamine and glutamate from the lumen as compared with glutamine from blood. Archives of Biochemistry and Biophysics 171, 662-672.

Wu G, Davis PK, Flynn NE, Knabe DA \& Davidson JT (1997) Endogenous synthesis of arginine plays an important role in maintaining arginine homeostasis in post weaning growing pigs. Journal of Nutrition 127, 2342-2349.

Wu G, Flynn NE, Yan W \& Barstow DG Jr (1995) Glutamine metabolism in chick enterocytes: absence of pyrroline-5carboxylase synthase and citrulline synthesis. Biochemical Journal 306, 717-721.

Wyss A, Wirtz G, Woggon W, Brugger R, Wyss M, Friedlein A, Bachmann H \& Hunziker W (2000) Cloning and expression of beta, beta-carotene 15,15'-dioxygenase. Biochemistry Biophysics Research Communications 271, 334-336.

Wyss A, Wirtz GM, Woggon WD, Brugger R, Wyss M, Friedlein A, Riss G, Bachmann H \& Hunziker W (2001) Expression pattern and localization of beta, beta-carotene 15,15'-dioxygenase in different tissues. Biochemical Journal 354, 521-529.

Yu S, Morris JG \& Rogers QR (2001) Effect of low levels of dietary tyrosine on the hair colour of cats. Journal of Small Animal Practice 42, 176-180. 